\title{
El arte según Diego Barboza: Fiesta, irrupción del cotidiano a través de la nostalgia
} \author{
Art according to Diego Barboza: Feast, irruption of the daily \\ through nostalgia \\ Albeley Rodríguez
}

ISSN (imp): 1390-4825

Fecha de recepción: 03/2017

ISSN (e): 2477-9199

Fecha de aceptación: 05/2017

\begin{abstract}
Resumen:
El siguiente texto se propone reseñar algunos de los aspectos más destacados de la actividad artística desplegada por el venezolano Diego Barboza.

Este artista tuvo, y continúa teniendo, relevancia a nivel internacional, debido a la singularidad de sus propuestas en el marco de los conceptualismos latinoamericanos. Cuando los lenguajes artísticos se inclinaban a la sofisticación del mainstream global, Barboza optó por enfatizar los valores y formas de la fiesta popular de las tradiciones venezolanas, en una traducción que la integró a nuevas estrategias de producción de significados, con influencia en la reflexividad en tor no a formas de ser social más conectadas con la vida en común, la alegría y la incidencia colectiva en lo político.
\end{abstract}

Palabras claves: Experiencia, Acontecimiento, Performance, Fiesta popular, Arte conceptual latinoamericano.

\begin{abstract}
:
This article outlines some aspects of the artistic work positioned by Venezuelan artist, Diego Barboza. Barboza relevance reaches an international level, due to his unique proposals within Latin American conceptualisms framework. When artistic languages moved to global mainstream, Barboza chose to emphasize values and forms of the Venezuelan traditions integrating them to new meaning production strategies with influence over social forms of being with the shared life and the joy and collective incidence in political thinking.
\end{abstract}

Keywords: Experience, Event, Performance, Popular Party, Latin American conceptual art.

\footnotetext{
Autora:

Albeley Rodríguez, (Mérida, Venezuela, 1928). Candidata a Doctora en Estudios Culturales Latinoamericanos por la Universidad Andina Simón Bolívar y Magíster en Estudios de la Cultura, Mención Políticas Culturales por la misma casa de estudios (2010). Tiene estudios de maestría en Museología (UNEFM, Falcón-Venezuela), y es Licenciada en Letras, Mención Historia del Arte, (ULA, Mérida, 2000). Fue curadora del Museo de Arte Contemporáneo de Caracas desde 2003 hasta 2015 y Directora de Posgrado de la Universidad de las Artes (Ecuador) entre 2015 y 2016. Es autora del libro Cuerpos irreales + arte insumiso en la obra de Argelia Bravo (2014).
} 
el arte es un continuo explorar, una búsqueda constante dentro de una realidad que aún me ofrece múltiples posibilidades

Diego Barboza

Me interesa mucho el sentido de las celebraciones populares, porque pienso que nuestra sociedad antes de la colonia era una sociedad de acción. Caza, pesca, poblaciones nómadas, todas las acciones ocurrían. Esto me da la idea de que el rito y la celebración están muy cerca de una manera de ser. Yo sustituyo el arte tradicional por un hecho. Escogí la calle en vez de la tela.

Diego Barboza

la cotidianidad humana solo puede concebirse como una combinación o un entrecruzamiento muy peculiar del tiempo de la rutina, es decir, del tiempo en en que todo acontece automáticamente, en el que tiene cumplimiento el código ciego, por un lado y el tiempo de la ruptura

Bolívar Echeverría

Con una poderosa inclinación hacia las artes desde muy pequeño, el venezolano Diego Barboza (Maracaibo, 1945 - Caracas, 2003) tuvo una formación como artista plástico que se inició a sus 12 años, cuando abandonó la educación formal para inscribirse en la Escuela de Artes Plásticas del Zulia, Venezuela -actualmente Escuela de Artes Plásticas Julio Arraga - en la que se hizo pintor. La curadora y crítica de arte venezolano, Katherine Chacón (2001, p. 29), señala que no percibe en su proceso un programa estético definido y coherente sino que, al contrario, entrevé un cierto desorden que, según apunta, le permitió al artista zafarse de la formación estabilizadora de un estilo para, más bien, anclarse en búsquedas libres. Barboza desarrolló una trayectoria sintonizada con los códigos del arte conceptual a finales de los años 60 en Caracas, con propuestas que requerían la participación del público e incorporaban el humor y el juego como factores disruptores de lo cotidiano. Éstas fueron reconocidas por la crítica venezolana del momento como planteamientos sin precedentes. ${ }^{1}$

La singularidad de las búsquedas de este artista - en aquel momento llamadas con frecuencia "no convencionales" - inició su mayor visibilidad y reconocimiento a partir de su desplazamiento a Londres en 1968, cuando se marchó para realizar estudios en el London College of Printing. Una experiencia con la que el artista ampliaría el circuito de relaciones hacia el ámbito internacional. Allí, inició la realización de los denominados por él mismo "acontecimientos de arte de calle" o "expresiones de calle" (Barboza, 1974, s/p). ${ }^{2}$

Entre estas "expresiones" se recuerda muy a menudo la primera: 30 Muchachas con

1 Es el caso de "Viva Medea o la cultura occidental" (Ateneo de Caracas, 1967), una obra en la que, estando todavía fuera de las prácticas conceptualistas, ya prefiguraban varios elementos de interés en los trabajos posteriores de Barboza. La obra consistía en una figura femenina hecha en madera pintada. En el pecho tenía un corazón, y en las manos una flor y una pistola. Sobre la cabeza reposaba un "Partenón en miniatura", y el rostro evocaba la imagen de una artista de los años 20. Entre sus piernas se veían retozar ratones. La pieza era manipulable, de modo que tenía compartimentos en determinadas zonas del cuerpo (corazón, rostro, piernas) que sorprendían al participante con sentidos ocultos. El humor se manifestaba en esta obra con juegos relacionados con la cultura burocrática moderna, a través de un "departamento de reclamo" que aparecía detrás del corazón de la mujer. También detrás del rostro de aquella figura había un espejo.

2 Ya, desde 1964, Diego Barboza tenía la inquietud de buscar denominaciones que excedían las existentes, para adecuarse con mayor precisión a sus planteamientos. "Arte conflicto"; "expresiones de calle"; "Acontecimientos de arte"; "Acciones poéticas" o "Poesía de acción", fueron algunos de los nombres que él le asignó a sus propuestas en distintos momentos de su producción creativa. La denominación de acción poética parece estar relacionada con el vínculo que el artista sostuvo con el poeta Julienne Blaine. 
redes (1970), ${ }^{3}$ una acción pionera entre los conceptualismos latinoamericanos, que consistía en la circulación de 30 estudiantes del College cubiertas con redes de colores por lugares frecuentados de Londres (como Plaza Trafalgar, Circo Picadilly o King's Road). Las chicas realizaban acciones comunes, como llamar por teléfono, ir de compras o, simplemente, circular por plazas, estaciones de metro y calles, entre el resto de los transeúntes. Este acontecimiento, según relata el artista en el video "Diego Barboza. Una vida entre redes”, pretendía simbolizar la ruptura de las restricciones sociales a través de la gente, las texturas y los colores, que servirían para "la captura y protección" (Galvis, 2003, 20'08”). Sin embargo, asimismo señalaba crítica pero lúdicamente, la estandarización sobre las costumbres cotidianas que, ya en aquel momento, comenzaba a imponer el mercado. De este modo, el artista inició una extensa y destacada trayectoria de acciones artísticas.

En 1971, realizó El ciempiés en el Speaker's Corner del London Hyde Park. Esta acción fue realizada emulando las fiestas populares de orden religioso que se efectúan en fechas específicas en Venezuela. Una especie de serpiente humana se desplegaba por el parque, articulada por una larga tira de tela colorida, y sostenida sobre las cabezas de los participantes que recorrían el espacio alegremente y en fila. Con ella Barboza buscó la expansión de su propuesta hacia lo que más tarde terminaría llamando "acciones poéticas", una especie de manifestación artística de participación colectiva y de exposición pública. Con esta metodología Barboza distanciaba, intencionalmente, sus propuestas de la idea de "público espectador»

3 En comunicación electrónica personal con Doris Spencer, compañera creativa y de vida del artista y, en la actualidad, responsable principal de la Colección Diego Barboza me acotaba "Muchos historiadores e investigadores de arte hoy, siguen diciendo que Martha Minujin fue la primera latinoamericana que hizo arte conceptual, a partir de los finales de los 70, cuando ya Diego tenía cuatro eventos relevantes entre 1970 a 1973" (Spencer, correo personal, 21 de febrero, 2017). con respecto a sus coetáneas internacionales de performances y happenings (Suazo, 2010, p. 2).

Es decir que, cuando Diego Barboza hacía referencia a las "acciones poéticas", ${ }^{4}$ se estaba planteando el alejamiento de la tendencia conceptualista $^{5}$ del mainstream concibiendo otro modo de nombrar esos actos comunales y celebratorios en lugares abiertos de la urbe, con los que apuntaba a la interrupción de la cotidianidad (Barboza, 1980, E-10) haciendo llamados de atención sobre la importancia de la vida en común, la presencia, la alegría y la incidencia colectiva en la esfera pública, esto es, en lo político.

\section{Esta dilatación de lo que Barboza se} propuso como hechos plásticos disruptivos, era para el artista una "captura para la liberación" (Galvis, 2003, 15'09”), que involucraba al ser humano desde la complejidad de la trama de sus emociones, con la espontaneidad colectiva, anclada en una nostalgia particular por los

4 En la conmemoración del décimo aniversario de su primera «expresión» 30 muchachas con redes, Barboza manifestó: "He decidido darle nombre a lo que hago. Lo llamo desde hoy "Poema de acción". Estoy convencido de que lo mío no es arte conceptual, sino un poema que queda en el aire, como una celebración» (Barboza en Pérez, 1980)

5 Este propósito de Barboza se sintoniza con lo expuesto por el artista y teórico del arte Luis Camnitzer, quien viene enfatizando que leer los conceptualismos latinoamericanos con lente de globalización es asumir distorsiones en la comprensión de nuestro proceso (Camnitzer, 1997, 180), despojándolo de necesidades y propósitos invisibles al conceptualismo del norte global, esto es, de nuestras condiciones políticas y los efectos que nuestros conceptualismos tuvieron en el contexto latinoamericano. Asimismo, Suely Rolnik también ha apuntado la particularidad de los conceptualismos latinoamericanos, alejándolos del estereotipo de obras con pronunciado carácter ideológico, la autora destaca su sutileza para fundar nuevas políticas de la subjetividad en medio de facetas de crudo terrorismo de Estado: "Lo que marca la diferencia de las propuestas más contundentes que se inventan en Latinoamérica durante el período es que la cuestión política se plantea en las entrañas de la propia poética" (Rolnik, [2005] 2010, 120-121) 


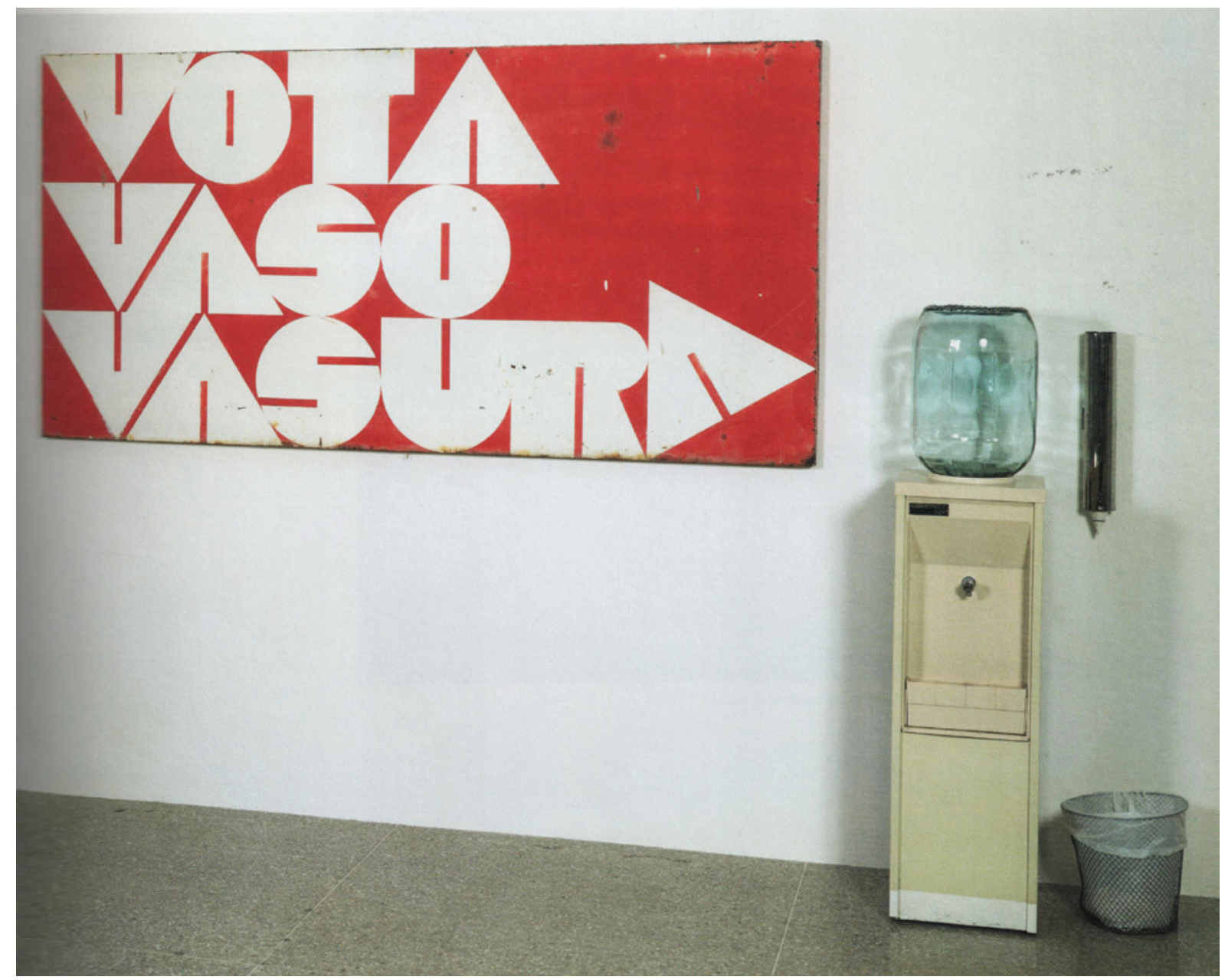

Figura 1. Registro de instalación. Diego Barboza, Vota vaso vasura, 1973. Colección privada. Imagen extraída del catálogo El festín de la nostalgia, Caracas, MACMA, MACZUL, GAN, 2001.

componentes éticos y la estéticos que ofrece la fiesta popular venezolana, ${ }^{6}$ y su ambición por la maduración de una conciencia sociopolítica colectiva. Fue a su vuelta a Venezuela a mediados de 1973, cuando Barboza, cargado de las nuevas experiencias, fue reconocido como uno de los más relevantes iniciadores del arte conceptual nacional.

El artista continuó entonces con las "acciones poéticas" recalcando, en ocasiones,

6 Aunque, quizá sea pertinente no pasar por alto que antes del regreso a su país de origen, las acciones de Barboza tuvieron un momento de viraje experimentador hacia la performance: Tal fue el caso de Cuidado King Kong (1972, Londres), porque esta acción cambió eventualmente, los procedimientos que Barboza venía desarrollando, ya que esta vez el trabajo fue realizado en el espacio privado de una galería y sin la participación abierta del público. aspectos de la tradición venezolana de carácter popular, simbólico y festivo, como sucedió en una versión nueva de Cuidado King Kong (1973), en la que incluyó elementos del ritual a María Lionza y del rito del tabaco ${ }^{7}$ o, como en la Caja del cachicamo - realizado en tres lugares distintos, diacrónicamente: en Caracas, en el Parque del Este y en la Plaza de Caricuao; y en Yaracuy, en el Centro Histórico, 1974. Barboza, en la Caja del cachicamo, sostuvo el

7 La reina María Lionza es una deidad venezolana campesina y afrovenezolana estrechamente vinculada a la naturaleza. Su figura proviene de una leyenda prehispánica que sufrió modificaciones que devinieron en un culto de corte sincrético y espiritista en el que se sostienen ritos y creencias católicas, indígenas y africanas. El rito del tabaco es un conjuro que se realiza con distintos objetivos relacionados con el amor y las relaciones afectivas, pero también con la riqueza y la prosperidad. 
mismo espíritu nostálgico y festivo que ya había expuesto en varias de las acciones efectuadas antes en Londres. En ella incitaba al público a participar a través de un baile realizado por dos personas que eran portadoras de dos largas tiras de color rojo salientes de los extremos opuestos de una misma "caja"; sobre las tiras se leía varias veces en letras blancas la palabra "cachicamo" y se podían escuchar los cascabeles que tenían cosidos. El artista concebía las tiras como las tripas del Cachicamo, con las que la gente podía jugar, danzar, correr, lanzar, gritar, comunicarse, según su deseo, "dando origen a una atmósfera de plasticidad creada por la acción colectiva de los participantes" (Barboza, 1974, s/p).

También, ya en Venezuela, realizó varios trabajos de otro tipo, siendo uno de los más memorables, por ser una de las primeras instalaciones de la historia del arte de ese país, Vota vaso basura (1973). Instalación que fue presentada en la primera edición del Premio Ernesto Avellán, Sala Mendoza. Se trataba de una valla metálica de publicidad, cuyo fondo rojo resaltaba las grandes letras blancas con la frase "Vota vaso vasura". La valla estaba acompañada de un filtro de agua, vasos de plástico y una papelera, aludiendo humorística y críticamente a la "fiesta democrática" de $1973,{ }^{9}$ las elecciones presidenciales de ese año.

8 En Venezuela se le llama cachicamo al animal americano que en otros países se le conoce como tatú, ayototztli, piche, cusuco, quirquincho o armadillo (nombre otorgado por los españoles), entre otros nombres.

9 Estas fueron las cuartas elecciones luego de la dictadura de Marcos Pérez Jimenez, y las segundas de ese período en las que un presidente le entregaba la banda presidencial al candidato del partido político contrario con mayor influencia electoral. En estas elecciones se confirmó el bipartidismo que imperó en Venezuela desde el "Pacto de Punto Fijo" - un acuerdo de gobernabilidad hecho entre partidos políticos, con la excepción del Partido Comunista de Venezuela (PCV), a pocos meses del derrocamiento de la dictadura en 1958 — hasta 1993.
Un dato importante, que le proporciona mayor consistencia a la estrategia empleada por Barboza, es que la campaña electoral de ese año fue de las más agresivas, en términos de producción de imágenes y proyección publicitaria, después del período dictatorial de Marcos Pérez Jiménez. Roberto Guevara, un connotado crítico y gestor de las artes en Venezuela, la llamó "el filtro de conciencia” (Guevara, 1978, p. 46).

Vota vaso basura (1973) también alentaba a la interacción del público con su instalación pero, sobre todo, apelaba a la "capacidad de hidratación de la sociedad" (Rodríguez, 2013, s/p) para producir una inversión crítica en la performatividad ${ }^{10}$ de los votantes venezolanos. De este modo, a través de un movimiento celebratorio, esta instalación daba cuenta de "un contexto histórico y político [...], plagado de dificultades en relación a la práctica de la democracia, dentro del que Diego Barboza se expresó con gran audacia estético-política” (Rodríguez, 2013, s/p). ${ }^{11}$ Una audacia que nos recuerda la potencia de las acciones performáticas,

10 Entiendo performatividad siguiendo al filósofo del lenguaje John Austin (1962), es decir, como una cadena de enunciados que, en su repetición, crean una conducta pero que, como ha apuntado Judith Butler, pueden ser subvertidos mediante otras acciones que resquebrajen el discurso naturalizado y preexistente (Butler, 2006).

11 A propósito del valor de esta obra, hace 4 años expuse mis consideraciones como investigadora-curadora, que era, del Museo de Arte Contemporáneo de Caracas, sobre la importancia de incorporar esta instalación a la colección de arte contemporáneo venezolano - dado que se había abierto la posibilidad de hacerlo- ante el Comité de Adquisiciones de la Fundación Museos Nacionales en Venezuela (Rodríguez, 2013, s/p). A pesar de que los argumentos fueron acogidos con atención, la respuesta se hizo esperar con muestras de desdén y negligencia de parte de las autoridades hasta, finalmente, dejar diluida la opción que, todavía hoy, resulta pesarosa. En la actualidad la obra pertenece a una colección privada ubicada fuera de Venezuela.

Acoto esta información con el propósito de hacer un alerta acerca de la necesidad de reflexionar sobre la diferencia entre las colecciones privadas y las pertenecientes al patrimonio público, y las repercusiones que cada una produce sobre los relatos, los imaginarios y el conocimiento que desarrollamos sobre el saber producido en nuestros países. 


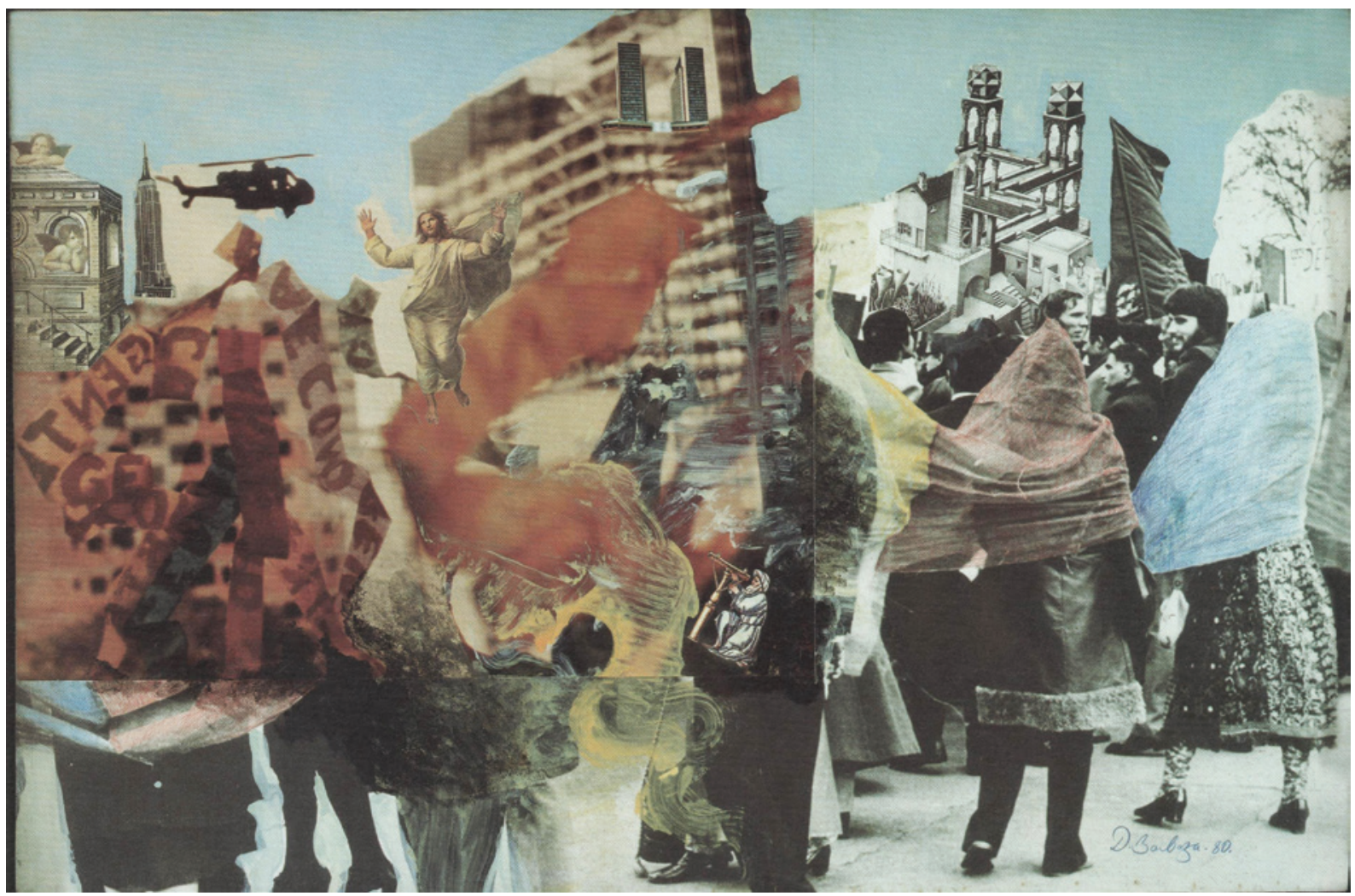

Figura 2. Diego Barboza, Guarandol (poema aerovisual), 1980. Fotografía intervenida con pintura industrial, creyón, collage de papel y barniz encolada a chapilla de madera. 66 x $100 \mathrm{~cm}$. Colección FMNGalería de Arte Nacional, Caracas. Imagen extraída del catálogo "El festín de a Nostalgia".

con respecto a la generación de fisuras en las convenciones, así como las disidencias puestas en acto, frente a los sistemas de poder (Taylor, 2012, pp. 26 -36).

Otra propuesta de mucho interés en la trayectoria de Barboza, fue Proyecto Guarandol - Poema aerovisual (1975, propuesto en la III edición del Premio Avellán), una acción que nunca pudo concretarse debido a los enormes riesgos que implicaba. Sin embargo, es interesante destacar que este proyecto fue registrado mediante otra acción titulada La oficina, en la cual lo daba a conocer desde un escritorio - con todos los implementos de bureau- a través de diversos materiales de archivo, como fotografías y correspondencias. Como documentos quedan el collage Guarandol I (Colección FMN-GAN, Caracas), y el impreso en fotocopia que Barboza acostumbraba a generar para hacer circular sus propuestas. En ambos se ve expresado el objetivo de lograr que un helicóptero volara sobre las torres de Parque Central, ${ }^{12}$ dejando colgar largas tiras de tela con la inscripción "Arte como gente I gente como arte". Las tiras se desprenderían después, para caer libremente sobre esa parte de la ciudad simbolizando una de las recurrentes utopías del artista: el poder de interferencia, abarcador y envolvente del arte sobre la vida diaria y urbana.

En 1976 Diego Barboza creó el Buzón de arte, un tabloide bilingüe que solo alcanzó dos números, pero que compilaba los prolíficos resultados del cultivo de otro medio disruptor de la vida de todos los días a través de la creación: el arte correo o arte postal — del cual

12 Parque Central fue un gran proyecto arquitectónico que comprendía la conjugación de un complejo habitacional, comercial y cultural de gran envergadura. Está ubicado en el Centro de la ciudad de Caracas. Fue emblemático para los ideales de la modernidad y los modelos de progreso urbano en Latinoamérica. Aunque hoy en día revele el carácter dramáticamente cosmético de aquella modernidad. 
él es uno de los más destacados representantes en Venezuela, junto con Dámaso Ogaz. Buzón de arte se emitió con la premisa de hacer un arte no comercial, que permitiera modos de relación a contracorriente de los medios de comunicación masiva y bajo el principio ético de que el artista está al servicio de la comunidad. A través de este tabloide, Barboza incurrió en una red latinoamericana en la que se hacían circular ideas clandestinas frente los actos de persecución y represión de las dictaduras (Padín, 1989, p. 17), con lo que buscaban contribuir a la justicia social, la búsqueda de la democracia y la protección de muchos artistas de nuestros países que fueron sus víctimas. Estrategias de los conceptualismos latinoamericanos que, como han seńalado Rolnik por un lado, y Camnitzer por otro, escapan a los modos del conceptualismo del mainstream (Camnitzer, 1997; Rolnik, [2005] 2010). Por otro lado, en la actualidad, se conservan los registros fotográficos de varias de las acciones realizadas por Barboza, la mayoría de ellos intervenidos, es decir, traspasando el mero carácter testimonial para tornarse otra obra plástica. Otra singularidad estratégica de este artista.

Aunque puede resultar enigmático, a mediados de los ochenta, el artista decidió regresar a la pintura, debido a que consideraba que el arte conceptual estaba representando límites para la comunicación con su público. Al parecer, realizó esta vuelta a la pintura con paso cauteloso -después del tiempo dedicado a la actividad conceptualista - por lo que su retorno fue primero mediado por el collage, la fotocopia, la acuarela y el dibujo, a los que había recurrido para el diseño y difusión de sus proyectos accionales y que fueron, desde su niñez, una importante herramienta de expresión que nunca abandonó. La pintura parece haber representado para Barboza, después de todos sus devenires, un reencuentro más con el pasado y su relación particular con otros aspectos de la nostalgia. Diego Barboza trabajó con elaborada insistencia sobre el mundo cotidiano, la reconexión con una ciudad en violento proceso de modernización, sobre una relación con el pasado que partía de cosas y lugares sin aparente importancia, esos que nos acompañan rutinariamente, y sobre elementos afectivos, performáticos y formales de la fiesta popular venezolana como canal para el desencadenamiento de acontecimientos en lugares despojados de memoria y vincularidad.

La distinción planteada por Bolívar Echeverría entre experiencia festiva y experiencia estética, como experiencias completamente diferentes, se ve relativizada por Diego Barboza en la mayoría de sus propuestas accionales. Echeverría apunta:
Conectada con la experiencia festiva de la ceremonia ritual de una manera muy especial -y también, por supuesto, a través de ésta, con la experiencia lúdica-, la experiencia estética es sin embargo completamente diferente de ella (Echeverría, 2001, p. 6)

Barboza acentuó la capacidad del arte para introducir reflexividad en una fluctuación sin delimitaciones, hecha desde el arte, entre las experiencias cotidiana, lúdica y festiva, para propiciar lo que Echeverría llamaría otra forma de ser social, no articulada por la lógica del capital. En las propuestas de Barboza, tal allanamiento del punto de vista estuvo intervenido por los sueños provenientes de lo concreto, pero que, desde esa concreción, se convirtió en fantasía para turbar acostumbrada la rutina. 


\section{Bibliografía.}

Austin, J. (1962). How to do thing with word, Cambridge, Harvard University Press.

Barboza, D. (1974). Expresiones. "La Caja del Cachicamo". Acontecimiento de Diego Barboza, Caracas, Publicación fotocopiada.

Butler, J. (2006). Deshacer el género, Barcelona, Paidós.

Camnitzer, L. (1997). "Una genealogía del arte latinoamericano" en Continente Sul- Sur, Porto Alegre, Gráfica Palloti.

Chacón, K. (2001). Diego Barboza. El festín de la nostalgia, 1955 - 2000 [Catálogo de exposición], Caracas, MACMA, MACZUL, GAN.

Diccionario Biográfico de las artes visuales en Venezuela (2005) Caracas, GAN, 118 - 119.

Echevería, B. (2001). "El juego, la fiesta y el arte" en Definición de la cultura, México, FCE.

Galvis, H. (2003). Diego Barboza. Una vida entre redes [Documental, $27 \mathrm{~min}$ ], Caracas, G2 Grupo Creativo.

Guevara, R. (1978). "Arte para una nueva escala", Maracaibo, MARAVEN.

Freire, C. (Coord.). (2015) "Diego Barboza/ Venezuela" en Terra incógnita. Conceitualismos da América Latina no acervo do MAC USP, Sao Paulo, Universidade de Sao Paulo.

Padín, C. (1989). "Latinoamerican Mail-Art" en Dámazo Ogaz, Co(Reo)Arte, disponible en Documentos/Redes Intelectuales en América Latina, Item \#140 http://redesintelectuales. net/documentos/items/show/140

Pérez, M. (1980). "Cumpleaños de "El Cachicamo"», Caracas, Diario El Nacional, 18- 05-1980, E-10.

Rodríguez, A. (2012). Diego Barboza. La impronta creadora de la acción [Catálogo de exposición], Caracas, Museo de Arte Contemporáneo. , (2013). Carta al Comité de Adquisiciones de la FMN, Caracas, Museo de Arte Contemporáneo.

Rolnik, S. (2010). "Furor de Archivo" en Rev. Estudios Visuales, Murcia, CENDEAC.

Suazo, F. (2010). Otro coincidente [plegable de la exposición], El Anexo Arte Contemporáneo.

Taylor, D. (2012). Performance, Buenos Aires, Autoimpreso Ediciones.

\section{Agradecimientos.}

Quiero expresar mi agradecimiento a la Colección Diego Barboza, especialmente a Marialejandra Maza y a Doris Spencer, por su disposición y apoyo. 